\title{
Latest Advances in Smart Components and Monitoring for Civil Structures
}

\author{
Thomas Richli \\ trichli@mageba-group.com \\ Mageba Group, Bulach, Switzerland \\ Antonios Chrysovergis \\ achrysovergis@mageba-group.com \\ Mageba Group, Bulach, Switzerland \\ Achilleas Athanasiou \\ aathanasiou@mageba-group.com \\ Mageba Group, Bulach, Switzerland \\ Niculin Meng \\ nmeng@mageba-group.com \\ Mageba Group, Bulach, Switzerland
}

\begin{abstract}
Rapid technical advances and the increasing demand for long design lives of civil structures of any kind make Structural Health Monitoring (SHM) increasingly popular for owners and designers for the valuable information it provides about structural performance. SHM offers a wide range of benefits including increased service life, improved maintenance planning, construction optimization, and risk minimization. For example, it can be used to verify design assumptions or to provide actual measurements in advance of upgrading and repair work. Depending on the objective to be achieved by SHM on any particular structure, systems can be simple and "portable", or sophisticated and comprehensive. SHM can be especially efficient and useful when the sensors that measure data are preintegrated in the design and fabrication of a bridge's key components - in particular, its bearings, expansion joints and dampers/shock transmission units. The benefits are further enhanced by ongoing developments in the communication technologies used to transmit data from the sensors on the bridge to the user's online interface. This paper briefly illustrates the use of this modern technology on bridges in Qatar, Switzerland, Norway, Canada, and India.
\end{abstract}

Keywords: Structural health monitoring; SHM; Smart components; Bearings; Expansion joints

\section{INTRODUCTION}

The use of modern structural health monitoring systems can be very beneficial in the construction, inspection, maintenance and renovation of structures in general, and of bridge structures in particular. By automatically measuring, recording, summarizing and analyzing key variables - 24 hours a day and seven days a week with little or no manual effort - it can play a key role in the overall monitoring and maintenance of a structure. It can even provide automatic notification (e.g. by SMS or email) to the responsible engineers when a measured value exceeds a pre-defined threshold value, providing confidence in a structure's ongoing condition and serviceability at any time. Useful data can also be provided during the construction stage, or to assist the planning 
of renovation or replacement works, making SHM useful throughout the complete life cycle of a structure or a component.

Recent technological developments in the field of structural health monitoring, particularly in relation to sensors and data logging, have greatly increased the potential of such technology to play a valuable role in civil and structural engineering - especially as it relates to critical infrastructure such as road and railway bridges. Continually progressing research work and the innovations of suppliers have resulted in the development of systems and solutions, which can greatly increase the effectiveness and efficiency of bridge construction, inspection, maintenance and renovation work (Treacy et al., 2019; Meng \& O’Suilleabhain, 2018).

In particular, there is a great potential to benefit from bringing together the key modern technologies that each can contribute so much to enhancing the life-cycle performance of structures - on the one hand, the SHM that so efficiently provides key data relating to movements, loads, etc., on the other hand, the high-tech components that accommodate, support, or control the same movements and loads. By integrating suitable sensors in the design and fabrication of key structural components such as bridge bearings, expansion joints, and seismic protection devices - giving rise to the development of so-called "smart" components - the long-term functioning and effectiveness of both the SHM and the key component can be optimized (Spuler et al., 2011; Islami et al., 2016).

Recent and ongoing examples of the use of such technology in various countries around the world are referenced below.

\section{APPLICATION EXAMPLES}

The following brief references to uses of the type of technology described above indicate the great diversity of application possibilities for this technology.

\subsection{Al Majd Road (Orbital Highway) Junction Bridges, Doha, Qatar}

This project highlights the benefits of incorporating SHM technology in the design and fabrication of a structure's bearings - components that are critically important for the structure's proper long-term performance. Qatar's new Al Majd Road (formerly known as the Orbital Highway) was opened to traffic in 2019, greatly improving traffic conditions around the country's capital, Doha. At one of the highway's main intersections shown in Figure 1 (left), a spaghetti junction where it crosses the Dukhan Road, it was decided to install an SHM system to monitor the condition of the various structures. The system is based on measurement of data from the bearings that support the various superstructures. All the sensors on 28 of these bearings, of the spherical type, are connected to 14 sensor nodes, as shown in Figure 1 (right). 

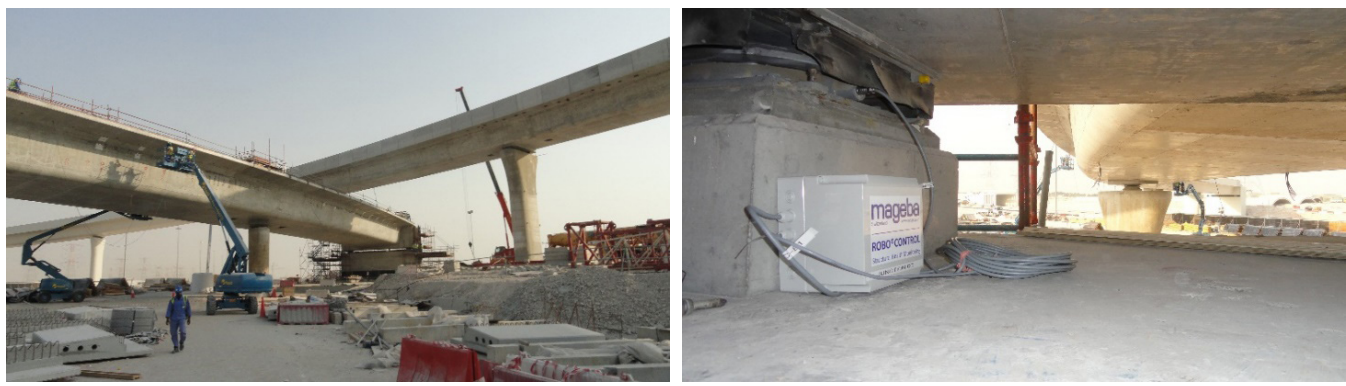

Figure 1: Construction of the main junction of the new Al Majd Road (formerly known as the Orbital Highway) in Qatar (left), and main sensor node of the project's SHM system, connected to bearings above (right)

The SHM system is designed to continuously monitor the load acting on each monitored bearing, around the clock. This enables it to immediately identify any change in loading conditions - e.g. should the load on any bearing increase or decrease due to structural damage/deterioration or ground settlement, either rapid or gradual? With threshold values defined (above or below, which the responsible engineers should be notified), risks to structure users can be minimized, and any structural damage or deterioration arising can be addressed before it develops into a bigger problem. An example of the data presentation on the system's secure online portal is shown in Figure 2.

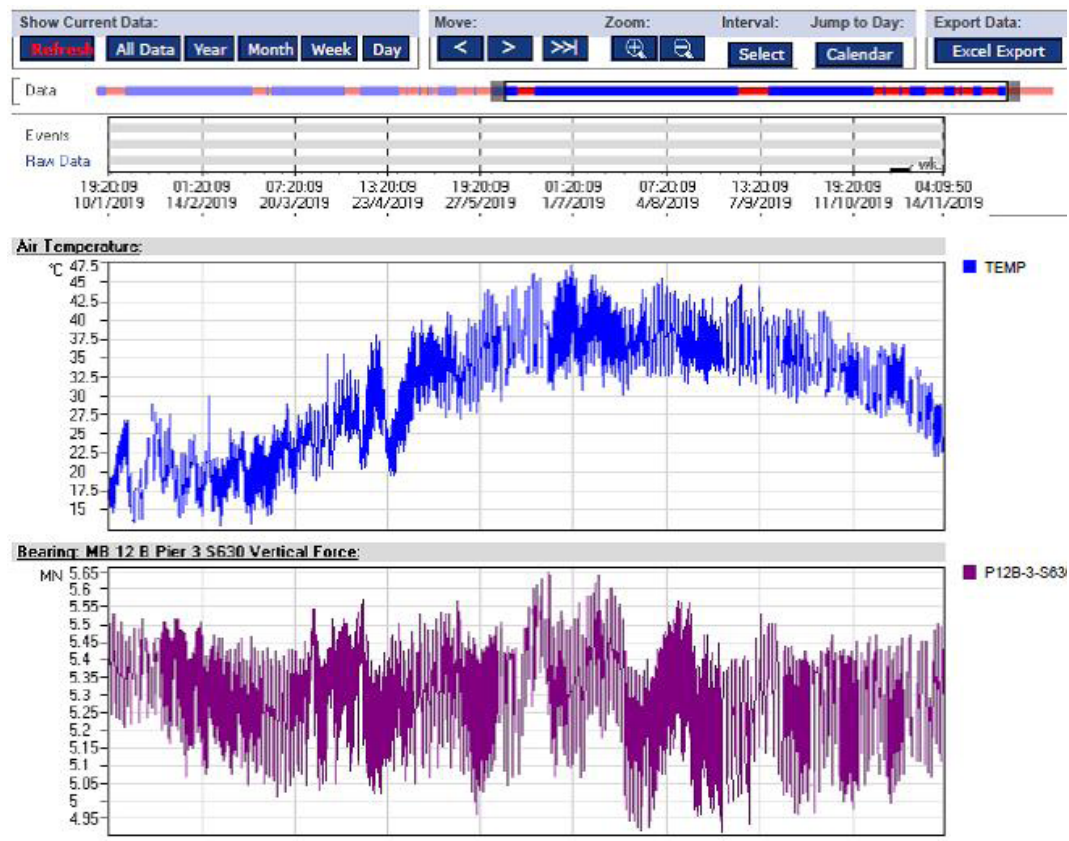

Figure 2: Sample presentation of recorded data relating vertical force carried by a particular bearing to temperature over a period of ten months

\subsection{Al Bustan South Viaduct, Doha, Qatar}

Doha's Al Bustan South viaduct (Figure 3, left), currently being constructed as a key 
element of the Qatar Expressway Programme, is a highway viaduct consisting of twin parallel structures, each carrying four lanes of traffic. Each of the parallel structures has a length of approximately $1.9 \mathrm{~km}$, with 34 spans - each typically $57 \mathrm{~m}$ long, but with lengths of up to $72 \mathrm{~m}$ at intersections. Entry/exit ramps at four locations comprise an additional length of $863 \mathrm{~m}$ of structure - here also multi-span viaducts with typical spans of $57 \mathrm{~m}$. The superstructures are supported by a total of 214 Reston-Spherical bearings (Figure 3, right), designed to support vertical ULS loads of up to $45,250 \mathrm{kN}$, to resist horizontal ULS loads of up to $15,600 \mathrm{kN}$ and to accommodate longitudinal sliding movements of up to $+/-260 \mathrm{~mm}$. In compliance with the local specification for bridge bearings, IAN 2006 (Rev. A2 Clause 3.6), two free-sliding spherical bearings were selected to be "smart bearings", with pre-integrated SHM sensors for connection to an SHM system.

To maximize the efficiency of data transfer, this is done by means of Lo-Ra (longrange) technology, avoiding the need for cabling work on the structure - an ideal solution when data is measured at low frequency (such as temperature-induced bridge movements).
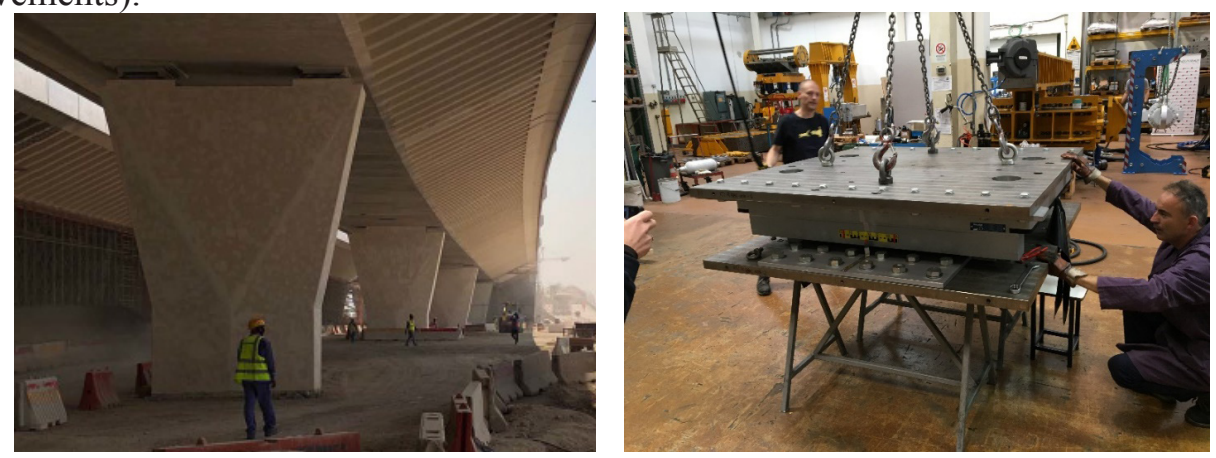

Figure 3: A small part of Doha's Al Bustan South viaduct (left), and one of the spherical bearings that support its superstructures - two of which are equipped with SHM sensors

\subsection{Lutrive River Bridge, Vaud, Switzerland}

The Ponts sur la Lutrive bridges over the River Lutrive in Vaud, Switzerland are parallel concrete bridges with a length of $395 \mathrm{~m}$ (Figure 4, left). As part of a recent bridge renovation project, it was decided to monitor the bridge's movement behavior, providing detailed information in support of maintenance and renovation works, particularly relating to the bridge's bearings and expansion joints. Due to the bridge's static design and nature - with traffic and wind having been found to have practically no effect on the bridge's movements, which thus depend primarily on thermal expansion and contraction - a lowfrequency SHM system was proposed, to record just one measurement every 30 minutes. The low frequency of data transmission made this project another good candidate for the use of wireless Lo-Ra technology to transmit the measured data from four longitudinal and four transverse displacement sensors - one of each at each superstructure abutment (Figure 4, right). An example of the movement data recorded at one abutment during a six-month period is presented in Figure 5. 


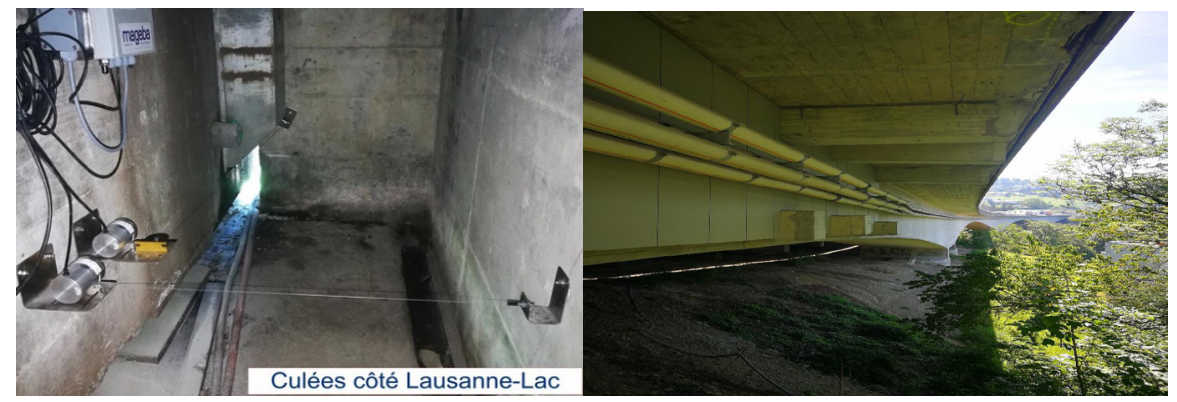

Figure 4: Lutrive River Bridge, Switzerland (left), and use of Lo-Ra wireless technology to transfer measured data from a sensor node to a gateway (right)

The use of wireless Lo-Ra technology avoided the need to install cabling between sensors and data acquisition unit, substantially reducing costs. Furthermore, the sensor nodes can be easily repositioned on other parts of the structure at a later stage. Here, data is transmitted wirelessly, from the sensors to the data acquisition unit, over a distance of approximately $400 \mathrm{~m}$. In good conditions - without significant obstacles - this technology can enable data to be sent wirelessly up to $15 \mathrm{~km}$.

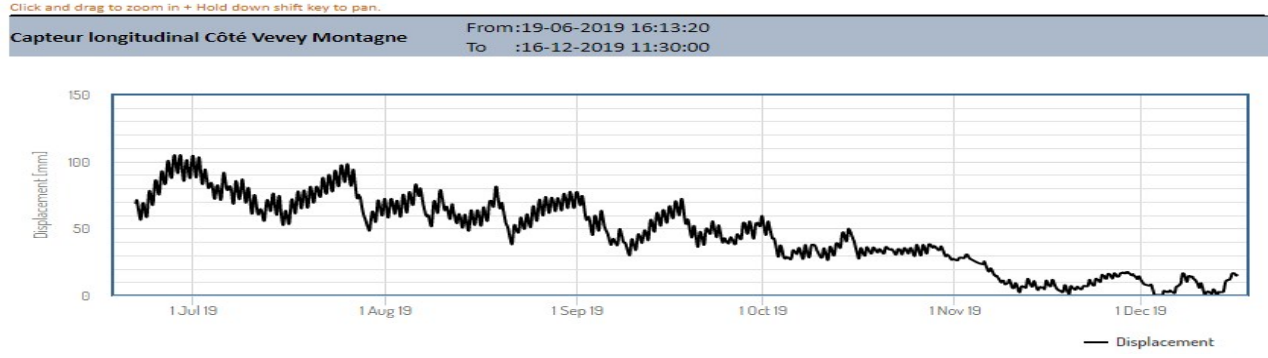

Figure 5: Longitudinal movements at abutment of Lutrive River Bridge during a sixmonth period

\subsection{Hålogaland Bridge, Norway}

The Hålogaland Bridge, located within the Arctic Circle in northern Norway, opened to traffic in 2018, forming part of the European Route E6 highway. The suspension bridge has a main span of length $1.1 \mathrm{~km}$, crossing one of Norway's many fjords. Its design required the installation of a Shock Transmission Unit (STU) at each of the bridge's towers (Figure 6).
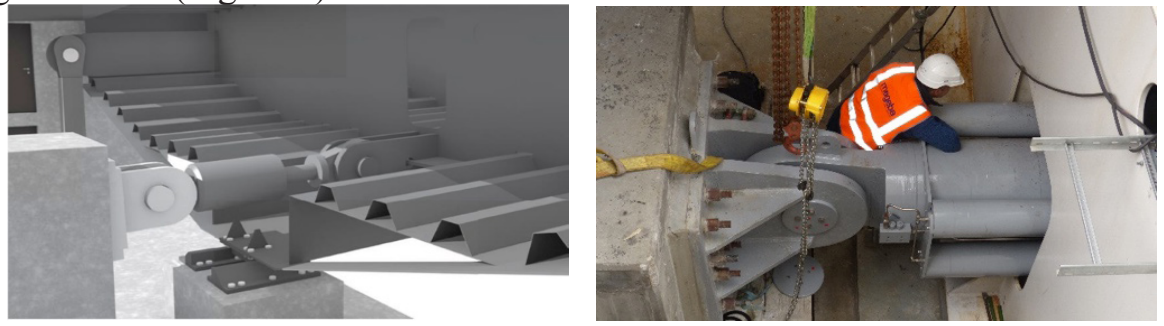

Figure 6: An STU at each tower of the Hålogaland Bridge controls superstructure movements - design representation (left) and during installation (right) 
To minimize the risks associated with the advanced structural engineering methods applied in the construction of this bridge, it was decided to install an SHM system. The system is initially based on measurement of data from the STU devices at the towers. An SHM system was designed to measure the longitudinal movements of the STUs, which have a stroke of $+/-450 \mathrm{~mm}$, and to also measure pressure and temperature inside these hydraulic devices. Each STU is equipped with one sensor for measuring movements, two sensors for measuring oil pressure within the device, and one sensor for measuring internal temperature. All sensors were integrated in the design and fabrication of the STUs at the production facility, maximizing durability and ensuring reliability. The system measures the pressure inside the STUs at a frequency of $100 \mathrm{~Hz}$, correlating the data against similarly monitored temperature and deck vibration data. This enables STU condition to be checked at any time, and for additional peace of mind, the system is also designed to provide immediate notifications should any predefined threshold values for movement or differential pressure be exceeded. In addition, the system also correlates the pressures inside the STUs against recorded seismic data in order to enable the actual seismic performance of the STUs to be evaluated following an earthquake.

The performance of these "smart" STUs is illustrated by the data shown in Figure 7 relating to temperature, displacement and force at the STU at one end of the bridge. This demonstrates how these variables are correlated, and analyses have shown that these devices are also sensitive, for example, to vehicle movements on the bridge, further showing how this use of STUs can help protect the structure against excitations.

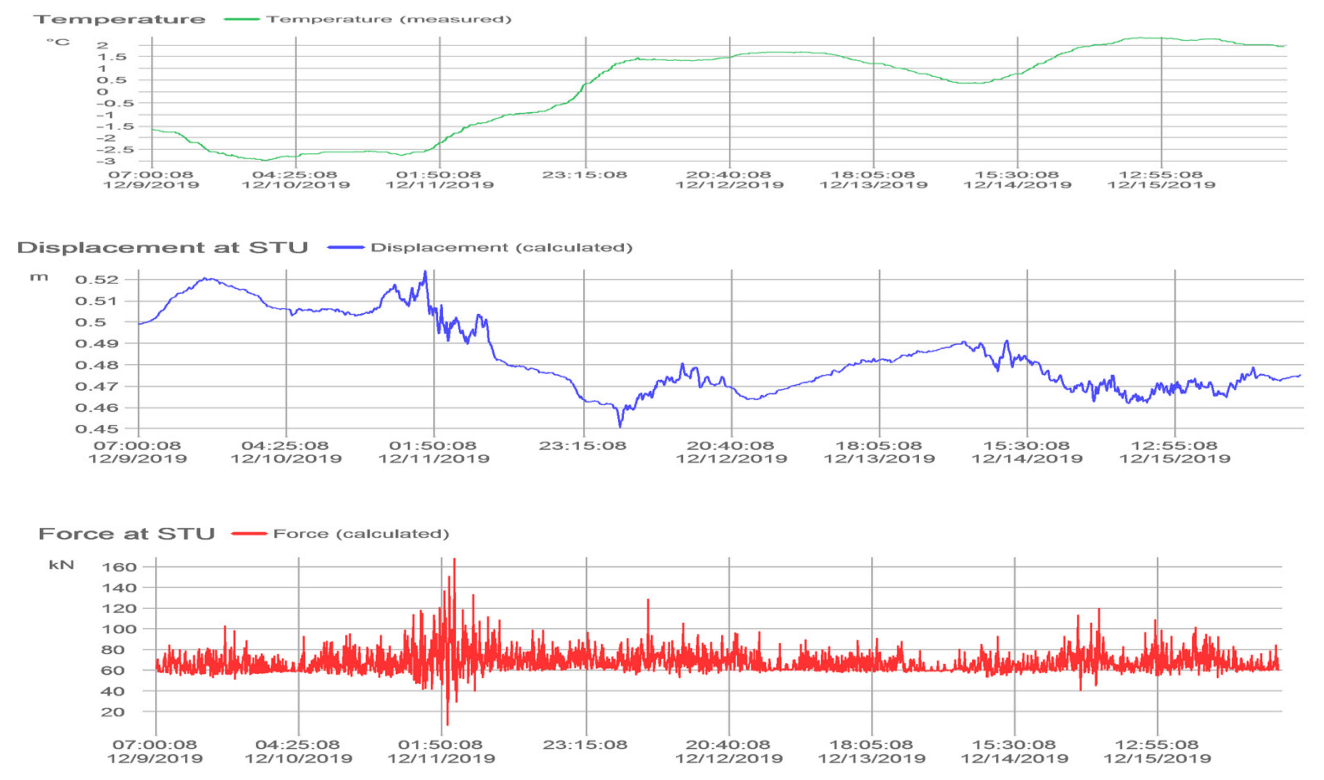

Figure 7: Data showing correlation between temperature, displacement and force at an STU of the Hålogaland Bridge

\subsection{The New Champlain Bridge, Montreal, Canada}

An example of the implementation of a far more extensive SHM system on a bridge 
construction project is the monitoring system of the New Champlain Bridge (Figure 8, left) in Montreal, Canada. The SHM system recently installed on this bridge over the St. Lawrence River and the neighboring Île-des-Soeurs Bridge is a comprehensive system that will conduct real-time monitoring of critical aspects of the two bridges, recording displacements, corrosion, strains and environmental conditions at carefully selected locations on the structures (Treacy et al., 2019). The numerous sensors include:

- 141 metal foil strain gauges (48 embedded and 93 surface-mounted to capture local strains);

- 44 draw wire displacement sensors (at expansion joints and bearings);

- 15 accelerometers (on deck/piers and cables);

- 6 tiltmeters (on pylon and piers) to capture rotations associated with horizontal movements;

- 22 corrosion sensors within reinforced concrete elements (Figure 8, right);

- Global Positioning System (GPS) units (incl. one at tower base and two at tower tops);

- Weather stations capable of measuring air pressure, temperature, humidity, rainfall, wind speed, wind direction and pyranometers, which measure solar radiation;

- 18 temperature sensors (8 for pavement, 10 for structure).
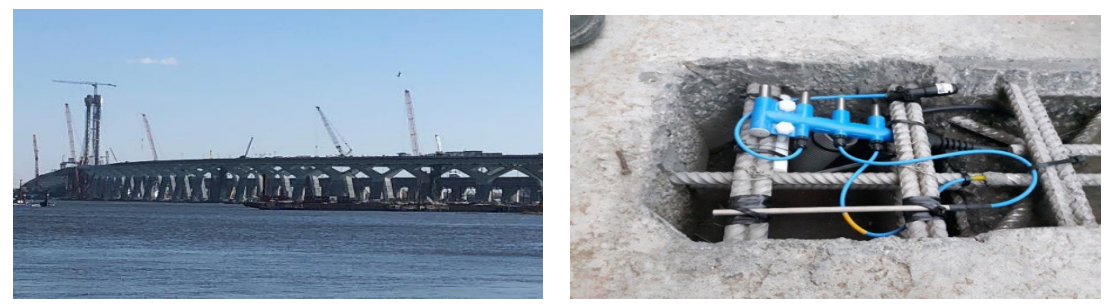

Figure 8: Construction of the New Champlain Bridge in Montreal, Canada (left), and one of the many corrosion sensors installed in the structures' concrete to monitor long-term deterioration (right)

The system includes 26 Data Acquisition Units (DAUs), which act as substations within the SHM network - 22 on the New Champlain Bridge and four on the Île-desSoeurs Bridge. Each DAU receives data from a cluster of sensors and is positioned accordingly. The DAUs, in turn, are connected to the master station by fibre optic cabling. This sensible use of modern SHM technology will help to optimize bridge maintenance efforts and will enable unexpected deterioration or changes in behavior to be immediately recognized and optimally addressed, for many years to come.

\subsection{The Kota Chambal Bridge, India}

Another recent example of the implementation of a comprehensive SHM system on a major bridge is that of the Kota Chambal Bridge (Figure 9, left) - recently constructed in Rajasthan, India, to carry a bypass highway of the city of Kota over the Chambal River. In this case, the sophisticated SHM system was designed to serve different purposes at different stages in the bridge's life cycle - first, during the construction stage to support the bridge's construction (incorporating a new approach to measuring displacement of 
the bridge's pylons) and subsequently, permanently, for inspection and maintenance purposes (Islami et al., 2018). This required the system to be modified, in particular in relation to sensor specifics and layout, following completion of construction. The permanent system is designed to continuously record the dynamic movements and stresses in the bridge (including in its stay cables - see Figure 9, right) along with the environmental factors (including traffic, seismic, wind, etc.) that may cause or affect these. It is also designed to, in real time, process, analyze and interpret the data, as well as to display the data and analysis results. The graph in Figure 10, for example, shows the accumulated movements from thermal effects alone (measured at a frequency of one measurement every two minutes, excluding micro-movements due to traffic or wind) to be about $25 \mathrm{~m}$ per year at one expansion joint location, or $70 \mathrm{~mm}$ per day. The system is also set up to provide a warning should a predefined "safe" value for any measured variable be exceeded.
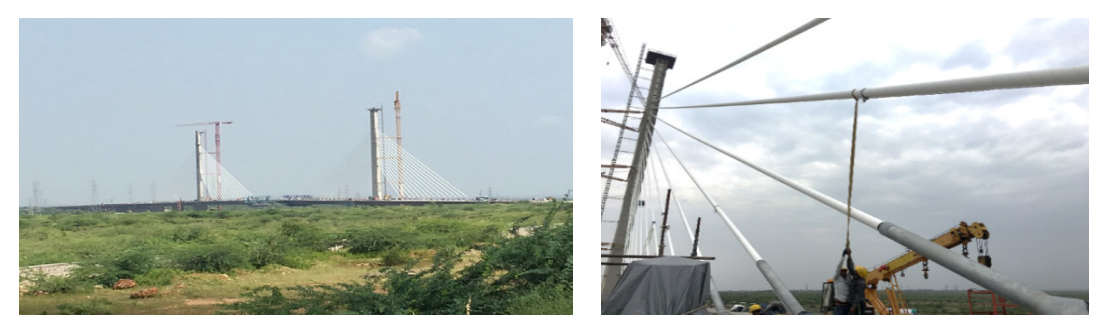

Figure 9: Construction of Kota Chambal Bridge (left), with monitoring of many variables including stay cable vibrations (the picture on the right shows forced vibration of a stay cable with an accelerometer)

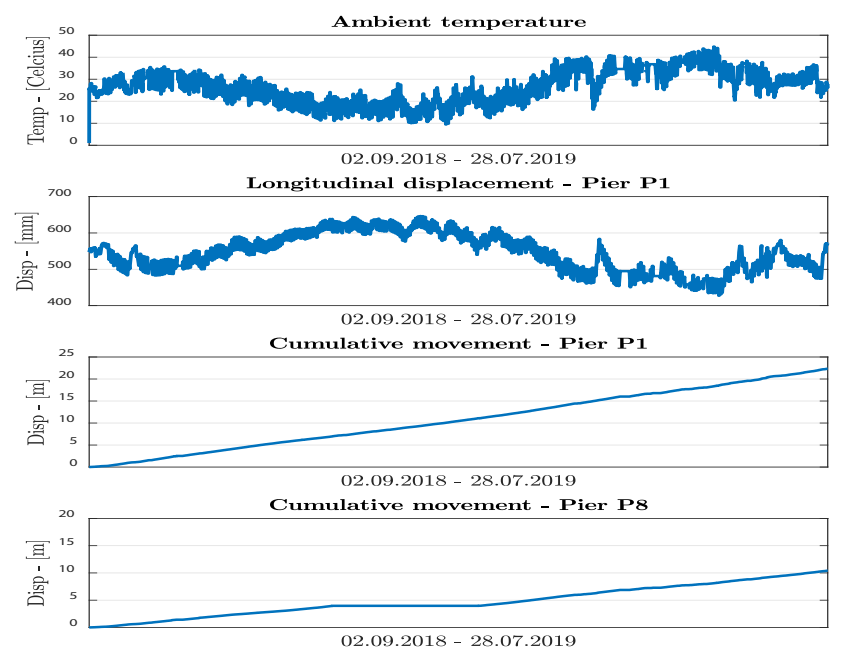

Figure 10: Example of recorded data from selected sensors on the Kota Chambal Bridge, showing clear correlation between low-frequency measurements of temperature and longitudinal displacement, as well as accumulated longitudinal movements at one location 


\section{CONCLUSION}

The use of SHM systems on bridges and other structures can offer great benefits to their asset management programs, efficiently providing data required for almost any purpose, at any stage of a structure's life cycle. The benefits of using such systems continue to increase as the technology is continually developed - with recent innovations including the use of wireless Lo-Ra (Long Range) transmission technology where low-frequency data measurements are required - e.g. to record temperature-induced bridge movements.

Integrating sensors in key bridge components - especially mechanical ones that accommodate or control bridge movements - offers several benefits. With sensors preinstalled, in factory conditions, work on site is reduced, the quality of installation work can benefit, and potential problems can be identified at an earlier stage. Such sensors, detailed and installed by the manufacturer of the key component with its specialist knowledge of the component, can be optimally implemented to provide not only data on the bridge's movements, condition and performance, but also on those of the component itself. Designing key bridge components to be "smart" in this way is surely, therefore, the future of this critical part of the bridge construction and maintenance industry.

\section{REFERENCES}

Islami, K., Meng, N. \& O’Suilleabhain, C. (2016). Smart bridge components (expansion joints, bearings and seismic devices) for intelligent infrastructure. Proc. 19 $9^{\text {th }}$ IABSE Congress, Stockholm, Sweden.

Islami, K., Savioz, P. \& Malekzadeh, M. (2018). Integration of SHM at an early stage in the design and construction of long-span bridges. Proc. IABSE Conference, Kuala Lumpur, Malaysia.

Meng, N. \& O'Suilleabhain, C. (2018). Automated monitoring of exceptional civil structures Case studies. Proc. IABSE Conference, Copenhagen, Denmark.

Spuler, T., Moor, G. \& Berger, R. (2011). Automated monitoring systems for bridge bearings and expansion joints. Proc. $7^{\text {th }}$ World Congress on Joints, Bearings and Seismic Systems, Las Vegas, the USA.

Treacy, M., Meng, N. \& Paciacconi, A. (2019). What added value can SHM bring to my construction project or structure maintenance programme?. Proc. SMAR Conference, Potsdam, Germany.

Treacy, M., Moor, G., Baillés, B. \& Paciacconi, A. (2019). A comprehensive Structural Health Monitoring System for the New Champlain Bridge. Proc. $9^{\text {th }}$ International Conference on Structural Health Monitoring of Intelligent Infrastructure (SHMII), St. Louis, Missouri, the USA. 